\begin{tabular}{c}
\hline Review of \\
ECONOMICS \\
and \\
INSTITUTIONS
\end{tabular}

\title{
Debt Sustainability Assessment: Mission Impossible
}

\author{
Charles Wyplosz \\ Graduate Institute of International Economics and CEPR
}

\begin{abstract}
It is highly desirable for policy makers, financial market participants and the public to be able to determine ex ante which debts are sustainable and which are not. Unsurprisingly, a literature has developed to provide answers. This paper argues that this is mission impossible. The fundamental reason is that debt sustainability is a forward-looking concept, with a very long horizon. Public debts projections are very sensitive to assumptions about growth, budget outcomes and interest rates. Not only it is impossible to achieve any degree of precision for such projections, but also it is generally the case that growth, budget outcomes and interest rates are endogenous to debts sustainability.
\end{abstract}

JEL classification: E43, E62, E37

Keywords: public debts, budget balance, sustainability

I am indebted to Anh-Nga Tran-Nguyen for suggesting the topic and providing me with much knowledge about debt sustainability analysis. In revising the paper, I benefited from useful suggestions by Andrea F. Presbitero and an anonymous referee. All the views expressed here are mines, as are the errors.

$凶$ Address: The Graduate Institute, Avenue de la Pais 11A, 1202 Geneva, Switzerland. (Phone +41 22908 5946, Email: charles.wyplosz@graduateinstitute.ch).

\section{Recommended Citation}

Wyplosz, C. (2011). Debt Sustainability Assessment: Mission Impossible. Review of Economics and Institutions, 2(3), Article 1. doi: 10.5202/rei.v2i3.42. Retrieved from:

http://www.rei.unipg.it/rei/article/view/42 


\section{Introduction}

Debt sustainability is a vexing issue. Its importance is immediately obvious but it escapes any easy definition. This situation is not unheard of in economics; price stability and full employment are examples of other crucially important policy objectives that cannot be simply defined. Yet, while price stability or full employment can both be measured with a reasonable degree of precision, debt sustainability cannot even be measured directly. Every country, therefore, must grapple with the issue of debt sustainability. In doing so, perverse incentives quickly emerge because there always is the possibility of default. Private borrowers are in the same situation as governments - for public debts - and states - for external debts - with one big difference: a private default is promptly sanctioned according to precise legislation under the control of courts, while public and external debt defaults are followed by litigations and negotiations within fuzzy legal rules and uncertain enforcement mechanisms. Uncertainty about the consequence of public and external debt defaults is a source of perverse incentives (formally called moral hazard) captured by the distinction between ability and willingness to pay. $\left.\right|_{1} ^{1}$ One consequence of these perverse incentives is that many countries do not have access to international markets and must rely entirely on official lending to finance their development needs. Another consequence is that countries that enjoyed market access prior to defaulting can typically promptly return to markets once an arrangement has been found ${ }^{2}$ Official lenders cannot avoid dealing with the debt sustainability issue. The multilateral organizations and the Paris Club operate on a case by case basis. Their approach is to encourage borrowing countries to adopt prudent strategies while being receptive to their development needs. "Prudent" and "receptive" are subjective attributes, however, which inevitably leads to controversies. It is natural to try and escape controversies by designing systematic and therefore universally applicable procedures. This is why, quite logically, the World Bank's International Development Association (IDA) and the IMF have developed formal debt sustainability assessment (DSA) procedures. IDA lending is now informed by a battery of criteria developed within the Country Policy and Institutional Assessment (CPIA) approach while the IMF and the World Bank have put in place a standardized DSA procedure designed to be routinely used as part of surveillance and lending operations. More precisely, they have developed two different frameworks, one for low income countries and another one for middle income countries. In fact there are two different but related procedures, one designed for countries with market access and another one designed for low-income countries which rely mostly of public financing.

1 This distinction is introduced in Bulow and Rogoff (1989).

2 The literature on the costs of defaults is vast. For a recent assessment, see Borensztein and Panizza (2009). 
The main differences are as follows. 1) In the case of countries with market access, the analysis concerns both the external debt and the public debt and, in the case of the external debr, it deals with its level while, in the case of low-income countries, it concerns only the external debt, which is measured in net present discounted value terms. 2) For low income countries, the DSA uses an explicit procedure to establish debt thresholds while the threshold is left open to discussion in the case of the market access countries; IMF (2003b) proposes to use the same standard procedure to both groups of countries. In spite of these differences, both approaches equally face the criticism that is the main point of this paper, which intentionally ignores these differences.

This paper examines the DSA procedure. The next section explains why it is mission impossible. Noting that sustainability is entirely forward looking, it argues that any practical definition is arbitrary and that any sustainability indicator will be both arbitrary and too imprecise to serve as a tool for policy prescription. Section 3 then examines the IMF's procedure, intended to deal with this impossibility principle by being both simple and transparent. Because of the 'mission impossible' nature of the exercise, however, the procedure seems to be evolving towards more complexity. Indeed simplicity may come at the expense of precision, which calls for increasing complexity. In addition, given the IMF's own definition of sustainability, the procedure requires adopting, formally or informally, the CPIA approach developed by the IDA, a source of opacity. The section also reviews other DSA approaches, some which emphasize simplicity at the cost of precision, others which go further in the direction of complexity at the cost of transparency. Arguing that simplicity and transparency indeed are essential to make the procedure acceptable, Section 4 develops a series of principles that lead to a simpler, less ambitious and less systematic procedure that seeks to replace arbitrary judgements with a framework for dialogue between the official lenders and the recipient countries.

The paper was initially written in 2005. Since then the IMF and the World Bank have developed and refined their DSA procedure into a Debt Sustainability Framework or DSF (see for instance IMF and World Bank (2009); Arnone and Presbitero (2010); Buffie et al., 2010; Di Bella, 2008). These innovations and improvements involve longer horizons (20 years), focusing on debt targets rather than annual budget balances, they allow for wider stochastic simulations and they take into account the growth-enhancing effects of public investment. Yet, they do not address the mission impossible criticism. 


\section{What is Debt Sustainability?}

\subsection{Definitions}

Debt sustainability aims at answering a deceptively simple question: when is a country's debt becoming so big that it will not be fully serviced? The question can be applied to the external debt or to the public debt. The analytics is identical once it is noted that the external debt is linked to the evolution of the primary current account balance just in the same way as the public debt is linked to the primary budget balance. This distinction will be blurred in the present section by referring to 'debt' and 'primary balance', without specifying whether it applies to public or external debts and balances.

The IMF's own definition of sustainability is: a debt "is sustainable if it satisfies the solvency condition without a major correction [...] given the costs of financing" (IMF, 2002, p.5). Solvency, in turn, needs to be defined. Debt solvency is achieved when future primary surpluses will be large enough to pay back the debt, principal and interest. More technically, solvency requires that the current debt plus the present discounted value of all expenditures does not exceed the present discounted value of all revenues (or, equivalently, that the current debt not exceed the present discounted value of future revenues net of non-interest expenditures).

The solvency definition is clear cut and has long been formalized, but it raises many implementation difficulties. The sustainability definition, as stated, is very vague.

\subsubsection{Solvency Issues}

Solvency, and therefore sustainability as it builds upon solvency, is entirely forward-looking. It is future balances that matter, not the past and not just the current debt level. Huge debts can be paid back, and small debts may not be sustainable, it all depends on what the primary balance will look like in the future, including the very distant future. In fact, most governments are indebted forever and many external debts remain high for decades running. For instance, Figure 1 shows the evolution of the British public debt, measured in percent of GDP. During the last 300 years, it never dropped below $20 \%$, reached $270 \%$ and its average stands at $113 \%$. It may well be that the debt has been pronounced unsustainable several times, but it was sustained in the sense that the British government never defaulted. We return to this example below; at this stage, we just note that dealing with the issue of debt solvency - and therefore sustainability - requires passing judgement on events that have not happened yet, that cover a very long horizon, measured in decades, and that are largely unpredictable,

The next difficulty is that the debt must be scaled somehow to the coun- 
Figure 1 - The British Public Debt - 1700-2011

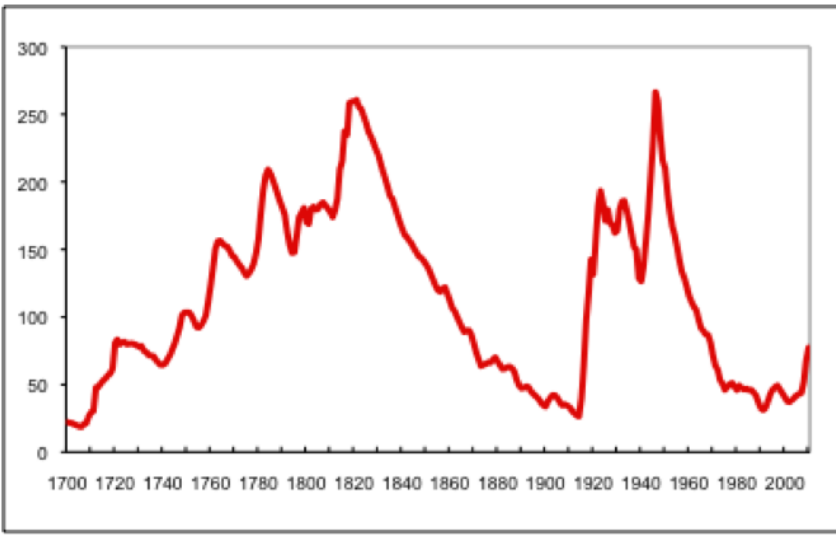

Source: Burda and Wyplosz (in press)

try size. The most popular approach is to relate the debt to the GDP, as in Figure 1, but the issue is not straightforward. It all depends what is the source of revenues. Public debts are serviced out of government revenues, so what matters is the taxing ability of the government, now and in the future. If the debt is external or public but partly owed to the rest of the world and/or in foreign currency, it will be serviced by the amount of revenues in foreign currency that the government can collect. There is little relationship between GDP and the amount of adequate revenues that can be collected so another scaling factor is required; it is customary to use exports, but this assumes that a constant fraction of exports can be used to service the debt. In addition, the scaling factor - GDP, exports or any other measure - must be forecasted over the relevant horizon; it not just the debt itself that must be guessed. There can be no pretense of precision, to say the least. Clear-cut, black-and-white conclusions are not credible. A further difficulty is that debts are rolled over. As the British example suggests, even long-term bonds are not long enough to cover quasi-permanent debts. ${ }^{3}$ As the debt is being refinanced, borrowing costs change, which must therefore be guessed as well. This requires making assumptions on the future course of domestic interest rates for the part of the debt that is issued in domestic currency; for the part that is issued in foreign currency, assumptions must be made regarding future foreign interest rates and country risk premia. Interest rates can change because of external conditions - including external conditions and occasional contagion from far-away events - which affect in unpredictable ways the solvency condition. In extreme, but not rare, situations, it may prove temporarily impossible to refinance the maturing debt, much less to issue new debt. This does not mean that the debt is unsus-

\footnotetext{
3 This is not entirely correct. In fact, the British government has issued perpetuities called consols, bonds with no fixed maturity. Once a large proportion of the public debts, consols are now an oddity and, anyway, most developing countries cannot issue long-term debts, at least in foreign currencies.
} 
tainable; it is a case of illiquidity. Illiquidity may force a debt default, even though the debt is sustainable, as previously defined.

\subsubsection{Definition of Sustainability}

Two qualifications of the IMF definition imply that sustainability is a more demanding requirement than solvency. The first qualification is to rule out a "major correction" in the primary balance. This probably refers to severe expenditures cuts or large revenue increases. The definition therefore includes liquidity constraints - a drying out of financing, either domestic or external - that require drastic adjustment. The second qualification refers to the "cost of financing". Financing costs are bound to change over time and are therefore unpredictable. In particular, they may increase as the debt rises, creating a vicious circle of the type mentioned in Section 2.2 below. As a consequence, a debt may be sustainable today and unsustainable tomorrow, and conversely. $\left.\right|_{4} ^{4}$ Thus the definition itself can be unstable. Finally, note that "major" is a matter of judgement, which means that the IMF definition is uncomfortably vague. The IMF's definition is at variance with the sustainability concept proposed by Arrow et al. (2004) in a very different context (the environment). Applied to the debt issue, their definition could be interpreted as suggesting that sustainability requires that the net worth of an entity (the government or the country), defined as the present discounted value of net revenues less the current debt, be on a not-decreasing trend. This definition differs from the IMF's in two important ways. First, it does not require solvency. Solvency is achieved if the net worth is nonnegative. The alternative sustainability definition does not rule out that, initially, net worth be negative as long as it is rising and eventually becomes non-negative and therefore meets the solvency condition.5 Second, and importantly for what follows, it does not imply any specific threshold for the debt.

\subsubsection{Making Definitions Operational}

There seems to be too many competing definitions of external or public debt sustainability. The Box below summarizes and interprets these various concepts. One theoretically-pure concept is solvency. The other theoreticallyclear concept, proposed by Arrow et al. (2004), is that the net worth (of the country for the external debt or the government for public debt) be (weakly) increasing. The second concept is less strict than the first one since solvency requires that net worth be always positive. These concepts cannot be implemented as such, unfortunately, because they require knowledge of the future evolution of the debt. IMF (2002) adds the requirement that solvency be always maintained without any major adjustment. Both because it relies

4 The European debt crisis offers examples of how, literally overnight, a public debt can change from being considered unsustainable by the markets and by public officials.

5 This point is formally stated in the Appendix. 
on solvency and because it rests on an unspecified limit to 'major adjustment', this definition cannot be implemented as such. As explained below, the definition is made operational by requiring that the debt does not exceed a threshold, to be further discussed. It should be noted that, if the threshold is conservatively set, the resulting definition is more demanding than the previous one (if the threshold is not binding, the definition is empty). The Arrow et al. (2004) concept can be made operational by ignoring the unobservable present value of primary balances and requiring that the debt-toGDP ratio be stationary. Since stationarity is difficult to assess in practice, the definition can implemented by requiring that the debt ratio be on a declining trend, which does not rule out occasional but temporary increases.

\section{Box 1. Theoretical and operational definitions of debt sustainabil- ity}

Let $b_{t}$ be the debt-to-GDP ratio at time $t$. Simplifying somewhat, the various definitions can be summarized as follows (see the appendix for a formalization). They are listed from the least to the most demanding.

- Debt serviceability: solvency plus no illiquidity. Illiquidity arises when the debt cannot be serviced at a particular point in time.

- DSA definition: $b_{t} \leq \bar{b}$, where $\bar{b}$ is a threshold.

- IMF (2002) definition: solvency plus no need for major correction.

- Solvency: the present value of $b_{t}$ becomes negligible for long horizons $\left(\lim b_{t} /(1+r)^{t}=0\right.$ as $\left.t \rightarrow \infty\right)$, where $r$ is the real interest rate. An equivalent definition is that the present value of primary balances $\geq b_{t}$.

- Arrow et al. (2004): net worth, i.e. the present value of primary balances less $b_{t}$, is not decreasing over time.

- Debt stationarity: $b_{t}$ does not grow without bounds. An alternative is that $b_{t}$ be (weakly) declining.

\subsection{An Impossibility Principle and Its Implications}

Because debt sustainability is a forward-looking concept, it cannot be assessed with certainty. In that sense, debt sustainability analysis (DSA) is impossible. At best, following procedures such as those presented in Section 3 below, one can make educated guesses but it is important to recognize at the outset that these are just guesses, no matter how sophisticated they may be. The implications of this impossibility principle are far-reaching.

Given the large number of guesses that are required to reach any conclusion, at best one can hope to make statements of the type: "there is a probability of $\mathrm{x} \%$ that the debt is sustainable at a particular horizon". Two 
aspects need to be highlighted at this stage. First, DSA can only provide probabilities. In some extreme cases, it can be $0 \%$ or $100 \%,{ }^{6}$ but generally it will be somewhere in the middle, i.e. relatively not informative. Put differently, DSA is a poor guide to policy. The fate of debt can solely guided by an event that may, or may not, happen.

Second, the probability that a debt is sustainable in the IMF sense is bound to change over time. For example, a highly indebted government that runs a sizeable primary surplus will see its probability of debt sustainability rise over time. This is the alternative definition proposed above. Conversely a government that starts with a low debt but systematically runs large primary deficits will have a declining probability of debt sustainability. Thus any statement on sustainability is only valid for a particular horizon. What should that horizon be? In theory, it should be infinite but, in practice, it is determined by the availability of reliable forecasts: if forecasts of primary balances, interest rates, GDP, etc. are extended to 20 years, the DSA will provide an answer at the 10 year horizon, much less than the infinite horizon that is logically required. Since 20 year forecasts are totally unreliable, the horizon is bound to be much shorter, but this undermines the whole analysis. This is a very serious problem.

As discussed below, a common practice to circumvent the horizon problem is to assume "everything constant" and extend past trends to an infinite horizon; this is convenient but totally unlikely, i.e. the probability of the assumed path is close to $0 \%$. Such exercises describe events that can never be taken at face value, in particular for policy purposes. Policies, especially those that impose costs on many poor people, cannot be shaped by very iffy possibilities. Another aspect of the impossibility principle is that sustainability as defined by the IMF requires making a judgement of when the debt is too big. Figure 1 reminds us that the debt can be very big and yet sustained. Recent work has pointed out that "big" is a relative concept $]^{7}$ It is generally considered that the developing countries cannot sustain large debts. Figure 2 shows that, indeed, the last peak in the mid-1990s was followed by a wave of crises. Will the recent rise in developing country debts, now above the previous peak, usher a new wave of crises? No one knows. Yet, framing the debt sustainability definition as the IMF does, makes it unavoidable to add a new concept, a debt ceiling. There is no precise way of defining what this ceiling can be. It must be based on the maximum amount of resources that must be collected to service the debt. This involves judge-

6 The collapse of the LTCM hedge fund is a useful lesson. In Section 3, we will point out the similarity between DSA and portfolio assessment, and will indeed discuss value at risk, a sophisticated technique directly borrowed from fund management. Resorting to the most advanced techniques available, LTCM managers - which included Nobel Prizewinner Robert Merton - had concluded that their investment was near $100 \%$ sure. As it turned out, an extremely rare conjunction of events occurred and LTCM, arguably the most prestigious fund at the time, went bankrupt.

7 For a recent assessment, including many references, see Cordella et al. (2010). 
Figure 2 - Public Debts in Industrial and Emerging Market Countries - 1992-2002

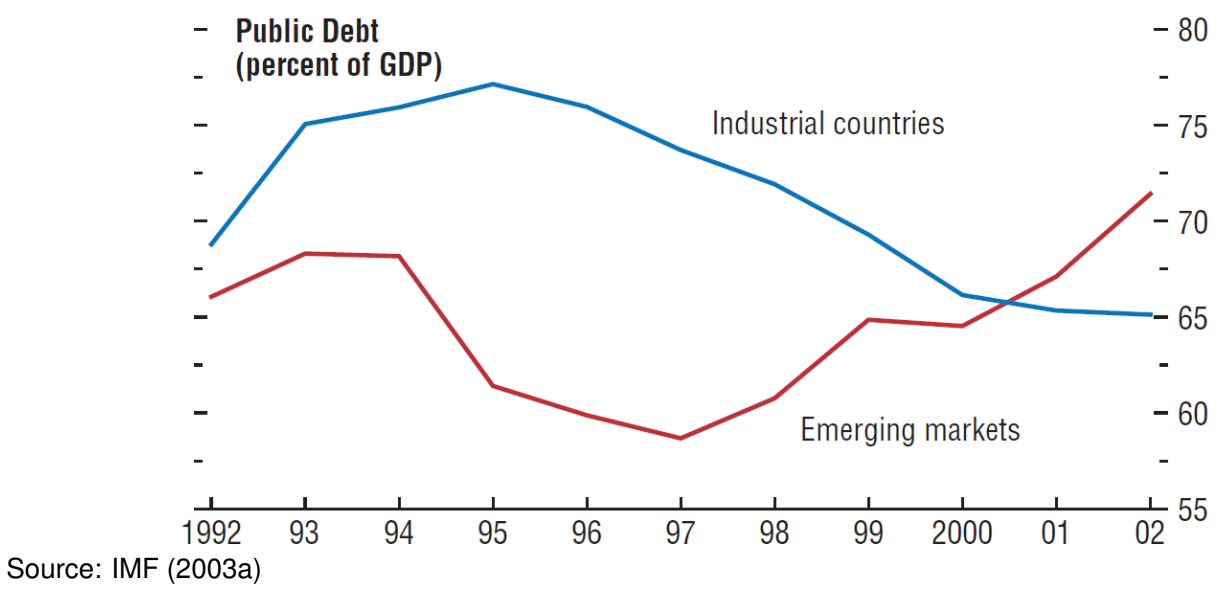

ment on economic costs and political acceptability that no one can evaluate with any degree of precision. This way of putting the question leads to another impossibility, that of assessing a debt ceiling.

Finally, rising interest rates increase the debt burden and reduce the probability of debt sustainability. A disturbing aspect of this linkage is that interest rates on public debts, whether in domestic or foreign currency, include a risk premium. The risk itself is related to the probability of default, i.e. to sustainability. The result is the possibility of a vicious circle that goes from a fear of debt non-sustainability to higher interest rates and to a higher probability of non-sustainability. ${ }^{8}$ What makes this observation disturbing is the possibility that the mere fear of non-sustainability makes non-sustainability more likely. Debt distress can be self-fulfilling. In particular, improper or incorrectly interpreted DSA may have a deleterious effect on debt sustainability.

\subsection{Debts and Inflation}

Inflation is a further complication that is often ignored in DSA. Even for external debt, inflation matters because the interest and exchange rates do not always reflect actual inflation. For example, if the exchange rate depreciates faster than prices, foreign currency debt becomes more expensive in domestic currency. The same happens when the interest rate on domestic currency debt increases by more than the inflation rate. Debt service becomes heavier. Conversely, when interest and exchange rates fail to fully reflect expected inflation and the debt is not indexed and in domestic currency, rising inflation temporarily reduces the cost of borrowing. 9 DSA should recognize

8 This process is studied in Blanchard (2005).

9 Buiter (1985) has shown that the great reduction of the British public debt over 19461970 has mostly been achieved through the inflation tax.A full account of this process includes regulated interest rates, i.e. some degree of financial repression. In countries with full capital mobility, this will not be possible. A wider discussion of the role of 
these various possibilities, but it is not standard procedure. One reason is that it would be technically difficult. Not only would it be necessary to forecast inflation but also expected inflation and non-neutralities, i.e. the extent to which the exchange rate and the interest rate fail to reflect expected inflation. While it is possible to forecast inflation over a relatively short horizon, say two to three years, forecasts beyond that horizon depends on policy actions that are yet to be taken. It may also be that international institutions, that typically do not condone inflation, are unwilling to speculate on what it could be and how it could be used to alleviate the debt burden 10

\subsection{Link with Early Warning Indicators}

A large literature has been devoted to early warning indicators. Like DSA, early warning indicators, which try to identify regularities that eventually result in a financial and/or currency crisis, must be forward looking. Crises, and therefore early warning indicators, are beyond the scope of the present paper. The only directly related question is whether a high debt level is a cause of financial crises, among the many other potential ones. According to the extensive survey in Hemming et al. (2003), the answer is: maybe. Formal statistical analyses provide conflicting results on this point. A problem is that they use current fiscal indicators, the budget balance or the debt level, as potential pointers of impending crisis. So far, DSA indicators have not been used, to the best of my knowledge, in early warning indicator estimates. It would be a good gauge of their empirical relevance.

\section{Approaches to Assessing Debt Sustainability: A Critical Review}

The impossibility principle developed in Section 2.2 represents a formidable hurdle. All approaches to DSA have to rely on assumptions about the future evolution of budget balances, GDP, interest rates, etc. The usefulness of the conclusions is directly related to the validity of these assumptions, which by definition are neither safe nor testable. This section starts with a critical description of the approach chosen by the IMF. It then presents and evaluates some alternative approaches.

\subsection{The IMF Standardized Approach}

The IMF has decided to systematically attach a standardized DSA to program design and to Article IV consultations. These DSAs examine both the public and external debts. The stated intention is to provide a simple, fully

financial repression is beyond the scope of this paper; see Reinhart and Sbrancia (2011). A well-known defense of some degree of financial repression is Rodrik (1998).

${ }^{10} \mathrm{Abiad}$ and Ostry (2005) provide evidence that inflation raises the primary budget surplus. 
transparent and standardized tool that can be readily applied to all countries. The World Bank has adopted a similar procedure. Unfortunately, the impossibility principle undermines these intentions. Simplicity is achieved at the cost of improbable assumptions; these assumptions are transparent, but they are less innocuous than they are made to be because the underlying complexity is concealed.

Focusing here on the external debt part of the exercise, the IMF approach includes the following four steps: $: 11$

i. A five-year central forecast, or baseline, of the variables that affect the evolution of the external debt: the primary account, GDP, interest and exchange rates, and inflation.

ii. The resulting evolution of the debt, as a share of GDP, over the next five years. This evolution is uncontroversial as it follows from the following accounting identity:

$$
b_{t}-b_{t-1}=(r-g) b_{t-1}-\text { primary balance }{ }_{t}
$$

Where $b$ is the debt-to-GDP ratio, $r$ is the real interest rate and $g$ is the GDP growth rate.

iii. Several stress tests that look at the effect on debt of adverse shocks affecting the variables forecasted in step (i). The shocks are as follows: first, each of three variable (the interest rate, real GDP growth and the primary current account) is changed one by one by one-half standard deviation over the same five-year horizon; then all the variables are simultaneously shocked by one quarter standard deviation each over five years; finally the exchange rate is assumed to be depreciated once by $30 \%$ at the beginning of the simulation period.

iv. The DSA concludes with a judgement on whether the debt levels implied by any or all of the stress tests are too high for the debt to be considered sustainable.

The result is a figure like Figure 3, which is based on the November 2005 review of the stand-by agreement with Colombia, see IMF (2005b). The figure displays various simulated paths of the external debt over the five-year period 2006-10: the baseline obtained in step (ii) and the effects of three of the shocks described in step (iii). These shocks are: a one-half standard deviation current account shock and the combined shock, both assumed to last the whole simulation period 2006-2010; and a 30\% exchange depreciation occurring in 2006.

\footnotetext{
11 This description follows the changes as described in IMF (2005a). More recent changes are presented in IMF and World Bank (2009) and on announcements posted on the IMF website (http://www.imf.org/external/np/sec/pn/2009/pn09113.htm and http://www.imf.org/external/pubs/ft/dsa/mac.htm)
} 
Figure 3 - Example of DSA: Simulated Paths of the Debt-to-GDP Ratio

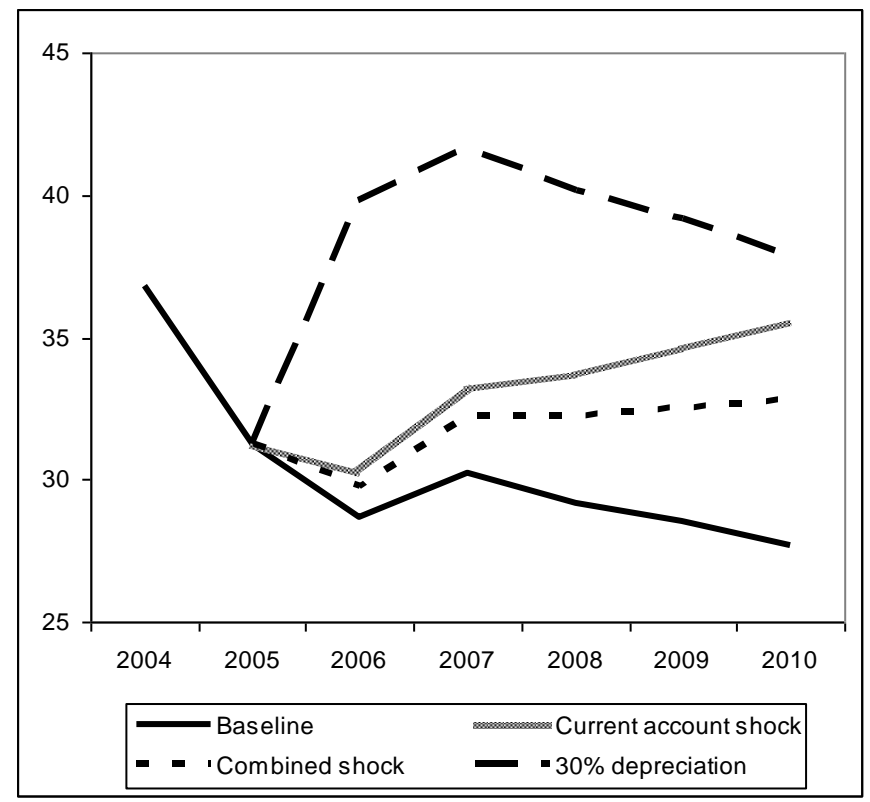

Source: IMF (2005b)

What to do with this information? Obviously, the baseline is no cause for concern. The stress tests, on the other hand, are less benign. The onetime depreciation raises the debt-to-GDP ratio by about $30 \%$, presumably because the external debt is in foreign currency. This is no a threat to sustainability, however, because the debt starts declining on the third year, most likely because domestic prices catch up with the rate of depreciation. More worrisome are the effects of a worsening of the current account and of the combined shock since the debt keeps on rising.

The unavoidable question is whether these simulations are sufficient a source of concern to warrant a policy reaction. Undoubtedly, were the debt ratio to keep on growing, the debt must eventually become unsustainable, but when? In addition, since the shocks are expected to last for five years, the debt should presumably decline beyond the horizon. In order to be able to draw any conclusion from this exercise, therefore, one must be able to conclude that the debt level reached at some point in Figure 3 is too high to be sustainable. This, in turn, requires establishing a debt threshold level beyond which danger is looming. Danger essentially means debt distress, i.e. financing difficulties or worse, partial or total default. In view of empirical results that show that the risk of debt distress rises with the size of debt, it seems indeed logical to establish a debt threshold beyond which the risks can be deemed unacceptable. This is step (iv).

Should there be a single threshold for all countries? Here again, empirical research shows that the probability of debt distress depends not just on the debt level itself, but also on a variety of factors, including the prevailing macroeconomic situation, debt composition and, importantly, the 
quality of economic and political institutions. A unique common threshold, therefore, is bound either to be too restrictive or too lax, depending upon the country characteristics. This is why the IMF uses as part of step (iv) an additional procedure called Country Policy and Institutional Assessment (CPIA). Developed by the World Bank, CPIA produces an index of governance quality for each country produced by the World Bank. ${ }^{12}$ This index, which ranges from 1 (lowest quality) to 6 (highest quality), is based on 20 indicators. It is updated annually, following a formal and elaborate process that involves the Bank's country teams and central departments. This index, which has been found to perform well in statistical tests, is used to classify countries into three groups: countries with a low CPIA index are ascribed a debt threshold of $30 \%$ of GDP, raised to $45 \%$ for the intermediate group of countries, and to $60 \%$ for the countries in the highest CPIA index group. These thresholds are chosen such that the probability of debt distress is $25 \%$ when they are reached. The list of country groupings is published, but the individual country indices have been treated as confidential. Following an expert review, the World Bank has announced that it will reduce the number of criteria from 20 to 16 and make individual ratings publicly available.

\subsection{Discussion of the IMF Approach}

Steps (i) and (ii) are mechanical implications of the IMF's forecasts. If the forecasts are accurate, the implied debt level is a reasonably safe prevision. The Fund reports on its own studies that show that the forecasts tend to err on the optimistic side, with equally optimistic debt predictions, see IMF $(2005 c)$.

\subsubsection{Probability of Worst Case Scenarios}

This is why, "in order to impose discipline" on the discussion, step (iii) looks at some worst case scenarios. Since "worst" can be virtually anything, the procedure attempts to be reasonable and transparent. To that effect, the shocks are precisely calibrated. How likely are 0.5 standard deviation shocks? The IMF argues that the probability of the debt exceeding the worst case on the fifth year is between $15 \%$ and $30 \%$, "which seems a reasonable balance between capturing the medium-term risks to debt dynamics without being so extreme as to be irrelevant for policy discussions" (IMF, 2005a; p.3). The emphasis is rightly put on policy implications, which raises the general question of what can be learnt from stress tests. There is nothing wrong with stress-testing. Indeed, it is a common approach to portfolio management, widely adopted in the financial industry, as explained in Sec-

\footnotetext{
${ }^{12}$ This procedure so far only applies to the low-income countries, presumably because it is in use at IDA. The Fund is considering applying it to countries with market access. The procedure, however, is non-transparent, presumably because it involves value judgement on the quality of policies and institutions. This aspect undermines the credibility of the thresholds.
} 
tion 3.3. Yet, the implications profoundly differ in the case of economic policy. In the finance industry, when stress tests report a danger zone, even a highly unlikely one, portfolio managers may decide to change the asset composition of their portfolios. The adjustment does not come for free, it implies lower expected returns, but this is the usual price to be paid for lower risk, a matter of investor preference. If investors are unhappy with their portfolio managers, they can easily change.

In the case of DSA, when stress tests signal a risky situation, the required adjustment is to improve the primary account. Inevitably, this calls for contractionary macroeconomic policies designed to compress demand. The costs take the form of falling incomes and rising unemployment. Importantly, the costs are borne by the population; citizens can vote their governments out of office - when the regime is democratic - but only ex post. A government's decision to react to events that have a $15-30 \%$ probability of occurring is considerably trickier than that of portfolio managers. It would be equally unwise for the IMF to suggest contractionary policies solely on the basis of DSA, whether as part of surveillance or conditionality. It is by no mean obvious that imposing restrictive policies with a (high) probability that they are not needed is less dangerous than accepting a (small) risk of a debt crisis. Stress testing does not mean the same thing at all in this context.

\subsubsection{Characterization of the Worst Case Scenarios}

The stress tests shake one variable at a time, and in one case all of them together, in the "bad" direction for five years. How likely is this pattern? It is unclear how the $15 \%-30 \%$ estimate is constructed. Does it take into account that each shock is expected to be maintained over consecutive 5 years? Does it take into account the fact that some of these shocks may be correlated? Letting the shocks last the whole five years assumes a $100 \%$ auto-correlation. The one-at-a-time shock assumes a zero correlation, the three-variable shocks assumes a correlation of $100 \%$. The information provided in IMF (2005a) does not shed light on this important question, suggesting that correlations are ignored.

What can be done about it? Here as with the threshold question, the proper technical response is to jack up the level of complexity, at the cost of reducing the intended transparence. Faced with the criticism that changes in just one of the variables that drive the debt process have historically typically affected the others as well, the normal tendency is to acknowledge the point and take up the challenge. This means using econometric techniques to estimate how, in the past, these variables have been responding to each other's shocks 13

The procedure is interesting and well-known, but it has many drawbacks. To start with, the estimates would now have to be conducted country

\footnotetext{
${ }^{13}$ Some papers have started to explore this issue, see Garcia and Rigobon (2004), Abiad and Ostry (2005) and Celasun et al. (2006).
} 
by country, an enormous task that would face serious data availability and comparability problems. Next, the quality of the estimates is likely to be poor in many cases, ${ }^{14}$ thus injecting a further dose of uncertainty regarding the meaning of the debt threshold, and therefore undermining its usefulness. In addition, this would turn a simple and transparent exercise into a highly technical and completely opaque procedure, with little assurance that the tests are plausible.

The challenge is formidable, possibly insurmountable ${ }^{15}$ It would be a serious mistake to go in the direction of added complexity, using the abundant paraphernalia of econometric instruments. Resorting to simple but less extreme stress tests (shocks with reasonable overall probability) would be an alternative, but the results could well be too mundane to be worth considering. The situation is, in fact, pretty hopeless. This is nothing more than an implication of the impossibility principle presented in Section 2.2.

\subsubsection{Borrowing and Growth}

An important linkage that is missing concerns the possible growth-enhancing effect of external borrowing. In theory, a country with low levels of human and physical capital stands to benefit from external borrowing. If the borrowing is wisely invested, the returns should more than cover the costs. The benefits come in terms of accelerated growth and catching-up. ${ }^{16}$

This linkage is explicitly ignored in the stress tests. This may look surprising given that multilateral lending is ultimately justified by its growthenhancing effect. One possible explanation is that the horizon is too short for the growth effects to materialize. The proper response to this argument is to lengthen the horizon, not to ignore the link. Of course, if debt distress occurs along the way, the expected growth bonus from external borrowing would be dissipated; this still does not justify ignoring the link. Yet another possible explanation is that borrowed resources do not systematically deliver any growth bonus. There is much evidence that the quality of policies and of political governance crucially matters in this respect, see e.g.

\footnotetext{
${ }^{14}$ The degree of precision of such estimates is generally quite limited. In addition, in developing countries data availability and quality problems are bound to arise, further weakening precision.

${ }^{15}$ IMF (2003b) suggests using the technique to derive fan charts, i.e. charts that depict the evolution of the debt following a shock by indicating the most likely path along with a range of possibilities. Fan charts have been popularized by the Bank of England as part of its inflation targeting strategy. This is how the Bank presents its inflation forecasts. Importantly, however, the fan charts are designed by the Bank of England's Monetary Policy Committee members, those who decide on monetary policy. Thus these fan charts are not the result of a complex econometric procedure but a snapshot representation of what policymakers believe. It is a great communication tool, which reflects the considerations that go into policy decisions, not outside experts' estimations of what is likely to happen.

${ }^{16}$ In terms of the formula presented in Footnote 22, the gap between the interest cost and the growth rate declines, and the debt accumulation becomes less destabilizing, or the gap becomes negative and the debt is spontaneously on a declining trend.
} 
Cordella et al. (2010). This aspect is partly taken into account by CPIA as the quality of policies and institutions are used to determine debt thresholds.

Given the overwhelming importance of growth, much more is needed. By limiting the role of policy and institution quality to the determination debt thresholds, DSA emphasizes the risks of overborrowing. Ignoring the conditions under which external borrowing can harm or boost growth amounts to asking the wrong question. If external borrowing is growth enhancing, the risk of over borrowing is small, possibly inexistent when the rate growth exceeds borrowing costs. If, instead, external borrowing does not exert any favorable growth effect, and possibly stunts growth, DSA is moot; countries in this situation should only borrow in distress situations and promptly pay back, before the debt burden becomes crippling. The record, as reported in Jeanne and Zettelmeyer (2001), is that the IMF's short term loans, disbursed to deal with emergency conditions, are in fact very long term due to quasi-systematic roll-over.

\subsubsection{Policy Responses}

The stress tests also assume that the government does not react to the shocks. This is in contradiction with much evidence that shows that the primary budget reacts to a rising public debt, which should presumably also have a dampening impact on the external debt ${ }^{17}$ Thus the worst case scenarios must be seen as a prediction that assumes that governments do not do what they usually do. This further reduces the plausibility of the tests.

\subsubsection{Country Policy and Institutional Assessment (CPIA)}

The IMF definition of debt sustainability, that debt levels not be 'too large', naturally leads to the need to establish thresholds. The observation that reasonable thresholds are likely to vary from one country to another next requires an explicit explanation of why some countries are more likely to suffer from debt distress than others. This explanation involves a large number of economic and political considerations, which involve explicit value judgements, a very uncomfortable undertaking.

The IMF-IDA response has been to look for statistical links between various causes of debt distress and the debt level. The two acknowledged background studies are Kraay and Nehru (2003) at the World Bank and an unpublished IMF paper. In line with the literature on the role of governance, ${ }^{18}$ the CPIA index is found to exert a significant effect on the probability of external debt distress, and it is reasonably precisely estimated. On the basis of this analysis, it is possible to assert that an improvement in the CPIA index reduces the probability of distress - which provides some support to the in-

\footnotetext{
${ }^{17}$ A good survey can be found Chapter 3 of IMF (2003a).

${ }^{18} \mathrm{~A}$ good reference is Manasse et al. (2003).
} 
dex - and even to compute by how much. This is not how CPIA is used in DSA, however.

The procedure instead uses the estimation to answer a different question: what debt level implies a $25 \%$ probability of debt distress? The answer cannot be based on the partial effect of the CPIA index only, it involves the whole estimation. If the estimation does a good job at explaining debt distress episodes, the answer will be precise and a good candidate to establish a threshold for each country. Unfortunately, while the effect of each variable is precisely estimated, together the three variables used in Kraay and Nehru (2003) (debt, CPIA index and real GDP growth) explain 23.4\% of the probability of debt distress. In a study that seeks to explain 163 episodes of debt distresses spread all over the world, this is a very distinguished performance, among the best in the literature, so good in fact that it is unlikely to be much improved upon. Yet, the fact that the analysis explains so little of the debt distress phenomenon implies that the answer is highly imprecise. Subsequent tests provided by Kraay and Nehru (2003) candidly confirm this conjecture.

For the time being at least, a further problem is that the CPIA index is not applied country by country. Instead, the countries are classified in three groups depending on their own CPIA index. The effect of governance is applied group by group, which implies that the effect is either exaggerated or underestimated for the countries whose CPIA indices do not lie in the middle of the range. This distortion rises with the distance from group means. This procedure is surprising. On the basis of the estimation, it is possible to compute individual debt thresholds. Why is it not done? One reason is simplicity; three thresholds are easier to deal with than country-specific thresholds. This is a weak justification for introducing serious distortions, which imply that the threshold cannot be taken seriously. Another reason is the political sensitivity of the CPIA index, presumably explained by the reluctance to discriminate too thinly among countries. This is understandable, but the result is that the DSA thresholds are too coarse to lead to firm policy conclusions.

\subsubsection{Sustainability Measure}

The debt level, suitably scaled, is arguably the correct measure for sustainability analysis. ${ }^{19}$ When tracking its evolution over time, however, a problem arises. Whenever the interest rate exceeds the economy's growth rate, the debt accumulation process is intrinsically unstable, this is precisely

\footnotetext{
${ }^{19}$ As noted in footnote 9, for the low-income countries, the procedure uses the net present value of the debt. While, in principle, this is a superior measure, its computation raises a number of delicate questions, which are not considered here. When we refer to debt levels, we do not distinguish between the debt and its net present value.
} 
why sustainability is an important issue. ${ }^{20}$ Two difficulties follow. First, relatively small changes in the real interest rate and in trend growth can tilt the debt path from stability to instability. Second, when the real interest and growth rates are close, small shocks can have dramatically powerful effects on the debt path.

The strength of this effect can be seen in Figure 4. The figure displays the baseline debt to GDP ratio and the effect of the DSA standard combined stress-test, both previously shown in Figure 3. The third case adds to the combined test the effect of an external interest rate set 3\% higher than assumed by the IMF. Increasing the interest indeed produces a sizeable effect. Comparing the combined shock effects with the lower and higher interest rate, we see that not only is the debt rising faster but, more importantly, that the debt ratio is not stabilized, possibly suggesting non-sustainability under any definition.

This example illustrates a simple fact: debt accumulation effects can easily be eye-catching and, in this instance, may raise considerable alarm, because the debt-accumulation process is inherently unstable. In reality, primary balances are adjusted, as the result of policy moves but also because of equilibrating reactions within the economy, and debt instability is usually taken care of. Of course, there exist many episodes of exploding debts, largely because small slippages do have dramatic effects as the result of the unstable nature of the process. This is why putative debt paths of the sort produced by the IMF as part of its DSA procedure can be misleading ${ }^{21} \mathrm{Sec}-$ tion 3.3 returns to this issue.

\subsubsection{Implementation}

IMF (2003b) discusses the (then) short experience with the implementation of DSA. It emerges that the DSA has not been as successful as its promoters intended: "with some exceptions, sustainability assessments have

\footnotetext{
${ }^{20}$ When the interest rate is lower than the growth rate, the debt to GDP ratio is stable and sustainability is assured. In the long-run, this is an unrealistic case because growth in excess of the real interest rate is a catch-up phenomenon (a country that displays a steadystate real interest rate lower than the growth rate is on the 'wrong' side of the golden rule in the sense that it saves and invests 'too much', suboptimally repressing consumption). In the short run, it allows many countries to run down the debt to GDP ratio. The interest rate may be lower than the growth rate during a period of fast growth (e.g. China or Ireland over the last decade) or during a period of accelerating inflation (e.g. the UK as shown in Figure 1).

${ }^{21}$ A related concern applies to the DSA for low-income countries. The chosen measure, the net present value (NPV) of the debt is very sensitive to interest changes, for the same reason. This measure is compared to the NPV of the debt threshold. Should the threshold also be adjusted? The IMF does not adjust the threshold, arguing that there are offsetting effects in terms of expected productivity adjustments. This is undoubtedly true, even though the timing and sign of these effects is not known. It is also true that the same effects will affect the path of the debt in the same way. It is inconsistent to adjust one measure and not the other. As noted, the difference can be very large.
} 
Figure 4 - Effect on the Debt to GDP Ratio of a Higher Interest Rate on the Combined Shock

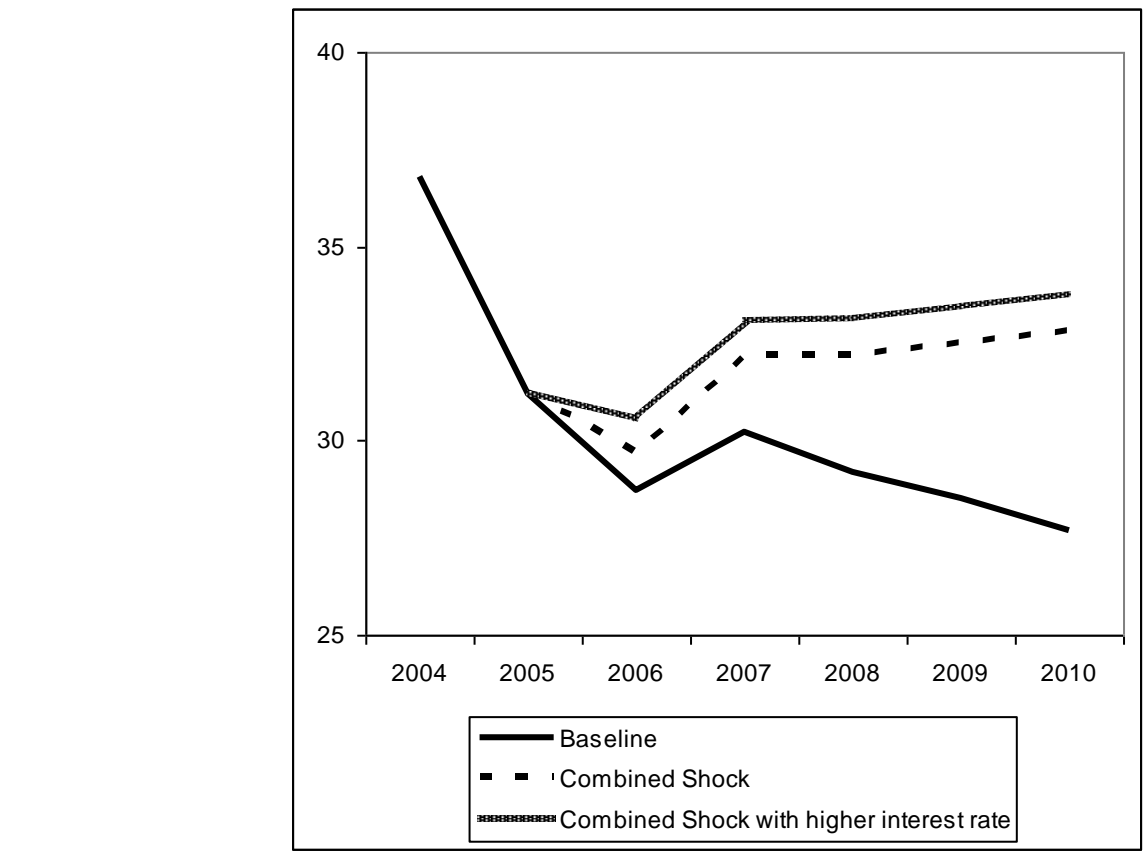

Source: Author's calculation based on IMF (2005b)

generally not been at the center of policy discussions between staff and national authorities. This may be because the sensitivity tests are considered too extreme to be realistic or, even if realistic, too extreme to warrant a policy response. Conversely, there remain concerns that the assumed shocks are too benign. Finally, from a presentational standpoint, debt sustainability assessments would have greater impact if they were integrated in the body of the staff report instead of being relegated to an annex." (p.15)

This situation reflects Staff's lack of comfort with DSA as currently practiced, which leads to reluctance to raise the topic with national authorities. The intended transparency of the shocks is marred by their low probability of occurrence. Another factor is the "black box" nature of the exercise, especially the assumptions about the economy's response to the shocks (in fact, it is assumed that there is no response, which is unrealistic as noted above. More importantly, Staff may be embarrassed by the question: "so what?". This question immediately brings to the fore the need to decide whether a temporary bulge in the debt is threatening. The answer is meant to be provided by the CPIA. The CPIA, however, is another "black box" with a large degree of uncertainty. The proposed thresholds are subject to too large a margin of precision to become a reliable guide for policy. Being unable to answer the "so what?" question, Staff downplays the DSA exercise. 


\subsection{Other Approaches}

Debt sustainability is an important a question that has long been studied. Until recently, due to the impossibility principle, there have been few attempts to design implementable approaches. The early ones acknowledged the sensitivity to unavoidable assumptions by stressing simplicity and transparency. Simplicity is justified since the need to make heroic assumptions implies that the conclusions will always be fragile. Transparency is necessary to allow users to understand what lies behind the result. More recently, DSA has moved towards more elaborate procedures, driven by the hope that empirical regularities can help make more reasonable assumptions and assess their plausibility.

\subsubsection{The Debt-stabilizing Primary Balance}

The classic approach asks what is the current account required to stabilize the debt (Blanchard et al., 1991; Buiter, 1985). The objective can be to stabilize the debt at its current level or at any other level deemed more desirable. This approach is simple, transparent and easily implementable because it requires few assumptions. In its simplest form, it looks at the current debt to GDP ratio and computes the primary balance which would permanently keep this ratio unchanged. It requires two assumptions: what will be the evolution of the real interest rate and what is the potential growth rate? Typically, past trends are assumed to remain stable over the indefinite future but shocks can be factored in, just as in the IMF's DSA.

In the end, IMF debt path projections and computation debt-stabilizing primary accounts are just the two sides of the same reasoning and involve the same assumptions. Both rest on the debt accumulation identity $b_{t}-$

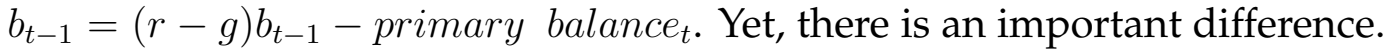
Debt path projections either indicate that the debt is stable or declining, in which case there should not be any sustainability issue, or that it rises, a sign of unsustainability. The debt-stabilizing primary account approach stops there. The IMF's DSA goes one step further by exploring adverse shocks. When these shocks imply a rising debt, new questions arise. Since the shocks are, by construction, temporary, a rising debt path does not mean unsustainability unless the debt becomes too large. This then injects a host of new issues, discussed in Section 3.2. The virtue of the debt-stabilizing primary account approach is to avoid these issues or, more precisely, to prevent them from becoming prominent.

Of course, the question of what is an appropriate level cannot be altogether avoided. Looking at the primary account that stabilizes the current debt assumes that the current debt is appropriate. Alternative debt level targets can easily be looked at. The question is vexing because theory does not provide any answer. The World Bank's CPIA is one attempt to provide a practical answer but, as noted, a weak one. This is why avoiding bringing 
the question into the limelight is a virtue.

How could the debt-stabilizing primary account approach be applied to the example of a major shock like the exchange rate depreciation presented in Figure 3? In the baseline case, the debt is assumed to decline, so the debt-stabilizing account is in deficit (1.7\% of GDP). ${ }^{22}$ The alternative approach looks at the initial debt level, at the current or projected interest and growth rates, and asks two questions: 1) What is the current account needed to keep the debt level unchanged as a percentage of GDP, ignoring capital inflows? ${ }^{23}$ 2) If the debt level is perceived to be too high, what would be current account required to bring it down to a particular level by, say 2010 ? This is a straightforward calculation.

As noted, the approach is formally identical to the IMF approach, but its interpretation is different, as illustrated in Figure 5. Since the debt is assumed in the baseline to decline, the figure looks at the combined shock. The corresponding external debt and primate current account paths are shown as "original". The primary account remains in small deficit as the debt takes the hit. Assuming that the authorities can control the primary account, the question is how they could react to stabilize the debt.

One possibility is to not allow the debt to change at all, maintaining it at its pre-shock level of 2005. This requires a large primary surplus, one that completely offsets the effect of the shock. The corresponding surplus is shown as "Stabilized 1" in Figure 5. The right panel shows that fully stabilizing the debt requires a huge primary account improvement when the depreciation suddenly increases the domestic currency value of the external debt. This tightening is relaxed when price increases catch up with depreciation.

Another possibility is to let the debt initially rise but to aim at returning it to its 2005 level by the end of the planning period, here 2010. The least disruptive way of doing so is to achieve a primary surplus that remains constant over the planning the period. This is shown in Figure 5 as "Stabilized 2 ". The primary balance now increases moderately, even though the shock is unusually violent. The downside is a bulge in the debt level.

Looking at the debt stabilizing primary balance, not just at the effect on the debt path, provides a different outlook on stress tests. First, it dedramatizes the shock effects. It shows that sustained but moderate primary balance corrections can insure sustainability - here defined as debt stabilization - in the face of even unusual shocks. Both experiments described in Figure 5 quickly return the debt to its pre-shock level, immediately in the "Stabilized 1" case, five years in the "Stabilized 2" case. Given the low probability of the shock, it would make sense to allow a slower return - improbable shocks do occur, but infrequently. Lengthening the horizon would

\footnotetext{
$\overline{{ }^{22} \text { The formula is pca }=(\text { interest rate }}-$ growth rate) $\times$ debt.

${ }^{23}$ Capital inflows are ignored both for transparency and because they tend to be too volatile to rely upon.
} 


\section{Figure 5 - Debt Stabilizing Primary Balance}

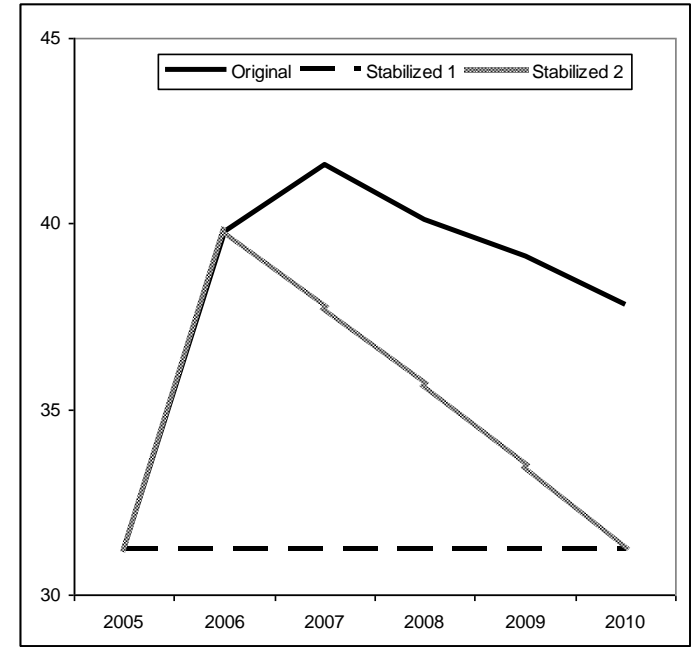

Debt (\% of GDP)

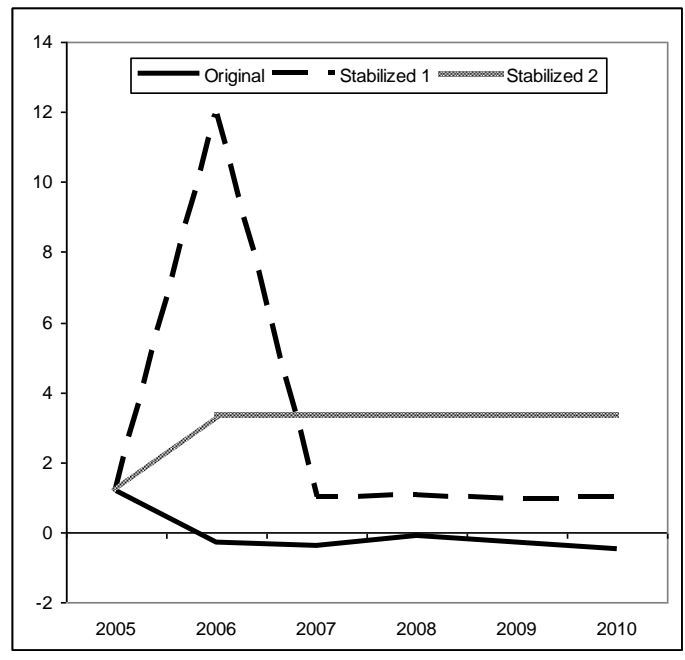

Primary balance (\% of GDP)

Source: Author's calculation based on IMF (2005b)

clearly allow for a small primary account corrections. In addition, adverse shocks are likely to be compensated sooner or later by favorable shocks.

Second, this approach also de-dramatizes the inherent instability of the debt accumulation process, which has been illustrated in Figure 4. Time permitting, even very large debt shocks can be dealt with through moderate primary account corrections. The reason is that a moderate sustained primary account correction produces a large cumulative effect as the shock itself 24

Third, this approach brings to the fore the policy implications. Obviously, "Stabilized 2" is more palatable, economically and politically; it avoids a massive spending contraction which is bound to result in a severe recession. It is a general principle that temporary shocks should be met with smoothing policies, i.e. policies that spread over time the adjustment costs. ${ }^{25}$ Merely looking at the original debt path in the left-hand side panel in Figure 5 may convey a sense of urgency that is not necessarily warranted. Of course, the "Stabilized 2" path assumes that the external debt bulge can be financed, which may not be the case for a number of countries, certainly not if they do not have market access. The answer is that the IMF was created precisely to provide emergency financing in the face of a temporary shock.

Fourth, the previous observation correctly attracts attention to the allimportant credibility issue. The downside of the "Stabilized 2" response is

\footnotetext{
${ }^{24}$ This is a consequence of the formula given in Footnote 22.

${ }^{25}$ Permanent shocks, on the other hand, need to be met by a permanent offsetting policy as soon as possible. This does not rule out a gradual implementation if the required policy involves adjustment costs, which are best spread over time.
} 
that the debt will only temporarily increase if the authorities can commit to a sustained primary account surplus. Put differently, the debt is sustainable only if the authorities can credibly commit to follow the assumed primary current account pattern. Failing credibility, the adjustment must be frontloaded, as in the "Stabilized 1" case.

Credibility is not absent in the IMF approach, it lies at the heart of the threshold determination procedure carried out by the CPIA. Yet, the example at hand illustrates a shortcoming of this approach (and may help explain why the Kraay and Nehru (2003) estimates explain a small part of debt distress episodes). It makes a big difference whether a debt level increase is merely the temporary consequence of a temporary shock or whether it results from endemic policy indiscipline. This is why it is essential that IMF lending be accompanied by credibility-enhancing conditionality.

This example illustrates the point made above: the IMF DSA procedure imagines shocks which may result in sizeable debt build-ups because the authorities are assumed not to react. We see that, if given time, relatively moderate primary account improvements can stabilize the debt (this is "Stabilized 2"). There should be no implication that the shock must be dealt with immediately as with "Stabilized 1".

\subsubsection{Value at Risk Stress Tests}

Financial institutions have developed procedures to explore the risks associated with portfolios, the value at risk approach. For financial firms, the issue is that they can go bankrupt. At the heart of this approach are two main ideas: that history allows evaluating the probability of various events or combinations of events, and that reactions should take into account both the possible severity of each event and its likelihood. This strikes as good sense, but it does not come for free.

The techniques used to measure the plausibility of various risks can be applied to the debt sustainability question. The IMF's approach takes a partial step in this direction when it shakes some variables on the basis of their previous behavior but, as noted above, it ignores how these variables react to each other. In principle, it is possible to go much further in this direction but at the cost of adding considerable complexity and opacity. The issue has been studied by Garcia and Rigobon (2005) and Celasun at al. (2006), so it is possible to give a sense of what is to be done and how it can be done. Rather than tailoring shocks on the basis of the historical evolution of individual variables, properly constructed stress tests take into account the historical interdependence among these variables. For example, in the cases displayed in Figure 3, the combined shock involves a simultaneous deterioration in the current account, the interest rate and GDP growth. This combination may be more or less likely than each of its components. For instance, if GDP growth systematically worsens when the interest rate increases, the combination is as likely as each of its components. Taking account such cor- 
relations - which may be positive or negative - allows for a better appraisal of the probability of the shocks that are considered.

This is the first step of the value-at-risk approach. It assumes that historical correlations are likely to be relevant in the future, a reasonable but not necessarily correct assumption. The next step then is to take into account all the estimated correlations and to imagine all the possible combinations of shocks. The procedure can be automated to randomly generate a very large number of shocks, literally thousands of them, some small and some big, some isolated and some combining many events. Crucially, the method associates each shock with a probability of occurrence. ${ }^{26}$ The last step is to associate with each shock the corresponding evolution of the debt, much as in the IMF's DSA, except that each debt path now comes with a probability of occurrences.

One can then ask the following question: at the three year horizon, say, what is the probability that the debt be between a high and a low level? The different combinations of high and low levels, with associated probabilities can then be presented in a "fan chart" like the one shown in Figure 6. In this figure different shades identify the probability of where the public debt can lie over the 2005-2009 horizon, ${ }^{27}$ the darkest part corresponds to an $80 \%$ estimated probability, with each lighter shade reducing the likelihood by $20 \%$. Obviously, the further out we look, the more uncertainty rises.

This presentation resembles the debt paths shown in Figure 3 but with important differences. In contrast to Figure 3, the shocks are not identified. This is a step forward since the shocks under consideration in Figure 3 are arbitrary, concerning both the choice of the variables and the magnitudes of the disturbances. The large number of randomly generated shocks is an adequate response to the criticism that the standardized DSA tests are arbitrary and therefore unlikely to be well suited to any particular country. Standardization is the consequence of simplicity, but its cost is arbitrariness and therefore limited credibility. In addition, one can judge at a glance how likely some of the dramatic scenarios are. The procedure provides more accurate estimates of the probability of each test. ${ }^{28}$

The procedure does not come for free, however. To start with, it is complex. Few developing countries are equipped to carry out such estimations and it would stretch the staff of any multinational institution to deal with a large number of countries. In order to provide reasonably reliable estimates, it requires good data, possibly going far back in the past; few developing countries provide such data.

Complex fan chart exercises may also provide an illusory impression

\footnotetext{
${ }^{26}$ Technically, this is called Monte-Carlo simulations.

${ }^{27}$ The chart displays the public, not the external debt.

${ }^{28}$ These estimates must still be taken with a grain of salt. Not only they assume that the future is driven by the same fundamental forces as the past, but they also provide from econometric procedures that face inherent accuracy limits.
} 
Figure 6 - Value-at-Risk Analysis: The Fan Chart for South Africa's Public Debt

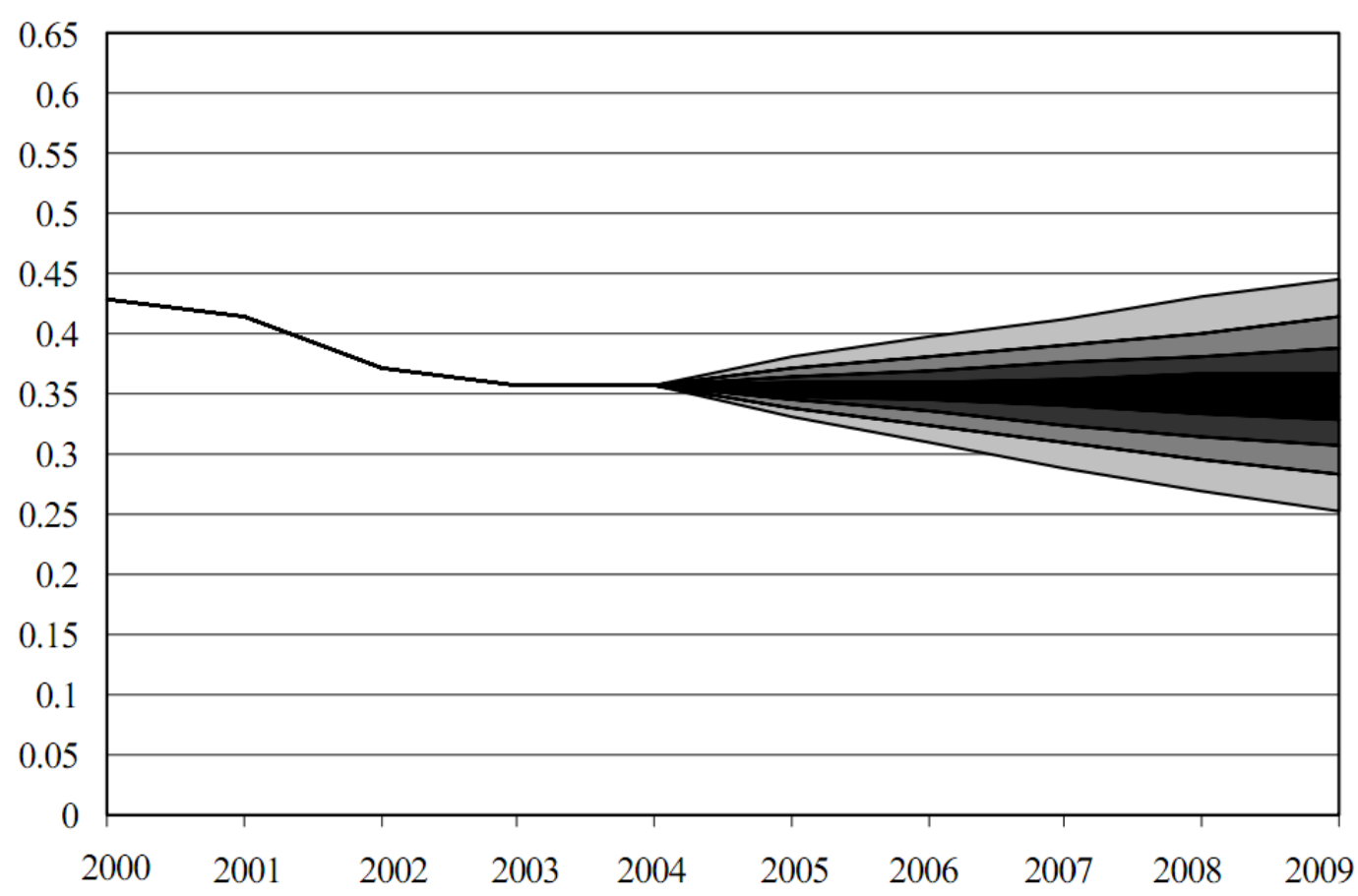

Note: External debt as a proportion of GDP.

Source: IMF (2005d)

that uncertainty is well understood. Fan charts do provide some useful information, but the precision of these charts is unknown. It depends on the quality of the data, on the performance of the underlying econometric analysis and on the relevance of history for the future. Importantly, perhaps, its "black box" flavor goes against the goal of transparency and is likely to deter policy action. This is one case where unavoidable complexity and opaqueness does not buy enough to be worth the effort. ${ }^{29}$

\subsubsection{Reaction Functions}

A key message from Figure 5 is that policies do matter. Adequate policy reactions can deal with shocks and these reactions need not be drastic; given time and commitment, small policy actions can do. This observation leads to the idea that debt sustainability is achieved as long as the authorities adequately react to shocks. Debt sustainability, therefore, can be seen as a consequence of the demonstrated behavior of the authorities.

Viewed this way, debt sustainability can be assessed by observing how each country's authorities behave. This leads to the estimation of policy reaction functions. In the area of monetary policy, such functions are known

\footnotetext{
${ }^{29}$ It may be ironic that the most advanced countries, which can and often carry out similar exercises, pay limited attention to them at decision-making time, while IMF (2003b) and IMF and IDA (2004) call for prioritizing DSA implications in the case of the less advanced countries.
} 
as Taylor reaction functions and have become routine. The approach has started to be applied to public debts more recently, apparently not yet to external debts.

The key question is whether the primary surplus is systematically raised when the debt level rises. It is possible to estimate the strength of this reaction and to determine a threshold beyond which the debt accumulation process is stable, which provides an alternative definition of sustainability. IMF (2003a) presents an overview of the emerging results on public debt reaction functions. While this work is still preliminary, it seems that many countries pass the sustainability test. This is generally the case for the advanced economies; for the emerging market countries, the reaction is adequate at moderate debt levels, probably not for highly indebted countries. ${ }^{30}$

The advantage of this approach is that it does not require the estimation of likely shocks and their respective probabilities. Nor does it require passing judgement on what is an acceptable debt level, avoiding the contentious CPIA process. The limit of the approach is, once again, a consequence of the impossibility principle. Debt sustainability is a forward-looking concept; future governments are not bound by past government behavior. Evidence of past sustainability, or the lack thereof, is not guarantee that future governments will continue to react in the same way. All that can be concluded is whether past practices are delivering, or not, debt sustainability.

It might be argued that simply looking at the existing debt level, or the history of past defaults, provides the same answer in a much simpler way. This is not correct. The debt may be currently high either because of undisciplined past policies or because of adverse shocks. In order whether a high debt is the result of bad luck or of bad policies, we need to disentangle these two assumptions. This is what reaction functions are designed to do. For instance, if the reaction function indicates that the authorities have systematically reacted in a stabilizing way to debt buildups, we can conclude that a high debt is due to bad luck. Inasmuch as bad luck does not strike again and again, in such instances, a debt can be very high and yet sustainable. This is the key lesson from Figure 1, confirmed by Figure 5.

One benefit of this approach is that it attracts attention to the issue of policy-making institutions. The best guarantee that the authorities will always react to shocks in a debt-stabilizing way is that their decisions be embedded in a framework that constrains them to do so. Put differently, sustainability requires that the debt level be systematically treated as a policy objective. This can be done in many ways.

One simple solution is the adoption of rules. This has been the case in the area of monetary policy with money growth rules or with the adoption of exchange rate anchors. Fiscal rules have been proposed to ensure public debt sustainability; the Stability and Growth Pact of the Economic and Monetary Union in Europe is one example. A huge and inconclusive literature

\footnotetext{
${ }^{30}$ See also Wyplosz (2005a) for a comparison of Brazil and the OECD countries.
} 
has explored the trade-off between rules and discretions. A more recent evolution is to explore more elaborate solutions in the form of institutions that are bound by strict objectives but also given some leeway to exercise discretion. Much progress has been achieved in the area of monetary policy with the adoption of inflation targeting and independent monetary policy committees. Similar considerations can be applied to fiscal policy, see Wyplosz (2005b).

\section{Review and Conclusions}

Along with price stability, low unemployment and balanced growth, external and public debt sustainability is an essential attribute of good macroeconomic policies. ${ }^{31}$ Along with these other attribute, its precise definition is elusive and its assessment is more challenging. This section takes stock of the previous analysis, develops a number of principles and advances some suggestions.

\subsection{Assessment}

The overview of the IMF's DSA and alternative approaches yields a number of conclusions.

- The various approaches to debt sustainability differ from one another in two main respects: the definition of sustainability and the way they attempt to deal with the impossibility principle.

- Strict definitions of sustainability start from the solvency condition, sometimes strengthening them - the IMF adds a no major adjustment condition - sometimes relaxing them - the Arrow et al. (2004) suggests eventually achieving solvency. Weaker definitions focus on stationarity of the debt level, usually scaled by GDP or exports.

- One way or another, implementation of these definitions requires making guesses about the future evolution of some variables. This gives rise to the impossibility principle: because the future is unknown, any debt sustainability assessment is only valid within the bounds of the underlying guesses.

- There is no way to escape impossibility principle. Any approach is based either on an analysis of the past, whose relevance is unknown, or on simulations of what the future might be, which is unknown by definition. Some approaches - e.g. value at risk stress tests - combine both procedures.

- The IMF approach combines simple and transparent procedures (computing debt paths based on scenarios) with more elaborate procedures (CPIA). The former are somewhat arbitrary and lay emphasis on debt thresholds.

${ }^{31}$ Debt sustainability may be seen as a pre-condition for all the other attributes. It is certainly not a sufficient condition. Whether it is a necessary condition remains open to debate. 
The latter attempt to extract information from the past but are of a "black box" nature.

- The impossibility principle does not provide support for the view that added complexity allows for more precise assessments. Value at risk stress testing, for instance, is state-of-the-art and technically clean but, as far as policy-making is concerned, the benefits are illusory. ${ }^{32}$ - Debt sustainability is intimately related to credibility. Credible authorities may adopt weaker definition of debt sustainability, eschewing the serious economic and political costs inherent to strict definitions. Credibility, in turn, emphasizes the role of policy-making institutions. - Policy conclusions drawn from DSA exercises must be considered with care. Sacrificing growth - in the short and even in the long run - to imprecisely known debt sustainability risks can be very costly. Trading off growth and debt sustainability will always remain more art than science.

\subsection{Principles}

As any guide to policy-making, DSA must be both simple and transparent. Simplicity is needed to allow every country - especially the less developed countries where growth crucially depends on external borrowing - to be able to produce its own analysis. Transparency is important because the range of possible debt distress causes is infinite. Vague and low probability threats cannot inform policy choices. This paper argues that DSA ought to rely on a number of principles.

\subsubsection{Accept the Impossibility Principle}

Except for obvious but extreme cases, it will never be possible to assert that a debt is unsustainable as defined by the IMF. Its own definition requires checking for solvency, which is impossible. It also requires passing judgement of what is a major adjustment, which involves assessing the willingness and political ability to carry out unpopular policies. This is turn calls for an evaluation of the impact of these policies and of the likely reaction of various segments of society, which depends on the political regime and, in democratic countries, on the electoral calendar. Finally, except for concessional loans, DSA is directly influenced by market sentiment, a source of unpredictable vicious - or virtuous - cycles.

\subsubsection{There Is no Trade-off Between Impossibility and Simplicity}

The impossibility principle rests on the uncertainty inherent in predicting the future. While eliminating this uncertainty is plainly not an option, a natural temptation is to reduce uncertainty by adopting sophisticated instruments. Most users are unlikely to grasp how these instruments func-

\footnotetext{
${ }^{32}$ This point is clearly made by Goldfajn in his excellent discussion of Garcia and Rigobon (2005).
} 
tion, however. Complexity means opacity. It is an illusion to think that some degree of opacity is worthwhile because even the most sophisticated instruments do not break the impossibility principle. Opacity, on the other hand, may result in the mistaken use of the instruments. Simplicity, which lays bare our lack of knowledge of the future, is a virtue in and by itself.

\subsubsection{Adopt a Workable Definition of Debt Sustainability}

Too many definitions do not just make life uncomfortable. They reveal that debt sustainability is and will remain a vague concept. In addition, there is a huge gap between theory and implementation. From an operational viewpoint, two main approaches are possible: the first one rests on debt thresholds, the second one on the evolution of debt levels. Given the impossibility, at least for the time being, to establish uncontroversial debt thresholds, DSA should rest on the second approach: a debt is sustainable if it is on a nonincreasing trend.

\subsubsection{Even Better, Replace Debt Sustainability with Debt Distress Avoid- ance}

That a debt level be trend-decreasing is neither necessary nor sufficient to avoid debt distress, however. Numerous debt crises occurred while the debt-GDP ratio was declining while many countries with long-rising debt levels have not run into trouble. In the end, the main reason for paying attention to the evolution of debts is the concern with debt distress. At the practical level, this distinction makes little difference but, at least, the concept of debt distress is clear.

\subsubsection{Recognize that Debts Are Not Necessarily Bad}

Many countries and virtually all governments are quasi-permanently indebted, for good and bad reasons. The view that debts should always be reduced assumes that all debts are bad, which cannot be generally true. Separately good from bad debts is another hopeless undertaking, but it is important to move away from the presumption that debt accumulation is to be avoided under any circumstance ${ }^{33}$

\subsubsection{Open the Process to Determine Whether Debts Are Excessive}

How to asses whether a debt is excessive? When the debt is traded, the risk premium provides a reasonable guide. It also provides the right incentive for governments to lower their debt levels. When the country does not have market access, there is no such gauge. Yet, the lenders are naturally entitled to have a view. Given that any assessment is bound to be controversial, as the CPIA exercise well illustrates, the multilateral institutions should have

\footnotetext{
${ }^{33}$ It is puzzling that the IFIs, which routinely emphasize debt reduction, exist mainly to grand loans and are the main creditors to many developing countries.
} 
a procedure to assess excessive indebtedness that is open and involves external experts $\sqrt[34]{ }$

\subsubsection{Time is of the Essence}

When current debt levels are considered excessive, debt distress avoidance calls for a declining trend. How steep should the rate of decline be? Obviously, bringing the debt down to a safe level before debt distress occurs is highly desirable, but it can also be costly in terms of growth and employment. There is a trade-off between a fast debt roll-back and the associated costs. This trade-off must be carefully assessed, taking due account of each country specificities.

\subsubsection{Accept risk}

Unless current debt levels are considered excessive, keeping them stable is likely to avoid debt distress under most plausible conditions. To be sure, there will always be exceptional events that will result in debt distress. Like all disastrous events, this risk must be accepted as a fact of life. Full guarantee that debt distress will never occur is illusory and a high level of protection is bound to be very costly.

\subsection{Suggestions}

\subsubsection{Use Both Approaches}

DSA rests on the debt accumulation process, which is nothing more than an accounting identity: $b_{t}-b_{t-1}=(r-g) b_{t-1}-$ primary balance . At $_{\text {. }}$ A the operational level, one approach is to make assumption about the evolution of the primary balance, interest rate $r$ and growth rate $g$ in order to track down the debt path. This is the IMF's DSA approach. The other approach is to ask what should happen to the primary balance to achieve a desirable debt path, given assumptions about the evolution of the interest rate $r$ and growth rate $g$. This is the debt-stabilizing primary account approach. How to choose which approach is more appropriate?

While the IMF also computes debt-stabilizing primary accounts, its policy analysis and graphical apparatus emphasizes debt path projections. The present paper has argued that the policy interpretation of debt path projections, already subject to the impossibility principle, spontaneously leads to looking for debt thresholds, another mission impossible. This calls for emphasizing the debt-stabilizing primary account approach.

In fact, there is no reason to choose one over the other. Both can be used, as Figure 5 shows. All that is needed is the classic distinction between tar-

\footnotetext{
${ }^{34}$ This is in line with the recommendations of the external panel that reviewed the World Bank's CPIA, see World Bank (2004).
} 
gets and instruments. The debt path is a target. The primary account is the instrument (assuming that the authorities can control it). The policy implications then follow naturally: DSA becomes a procedure that explores the debt path effect of various settings of the primary account instrument. What should this combined approach include and what assumptions should be made?

\subsubsection{Parameter Settings}

A baseline projection, such as carried out by the IMF, shows how the debt accumulation unfolds on the basis of the currently foreseen primary balance, exchange, interest and growth rates. Associated to this projection, it is straightforward to compute the primary balance that would stabilize the debt under current conditions, as well as the primary balance required to lower the debt to GDP ratio when the current level is perceived excessive or when the authorities find it uncomfortable.

The baseline should not mean to be a forecast, only a statement of where current conditions lead to. Currently the IMF provides two baselines: one that is based on Staff forecasts and one that is based on historical trends. None of them is adequate. Staff forecasts introduce a degree of arbitrariness. Indeed, IMF (2003b) reports a tendency for these forecasts to err on the side of optimism, for various reasons that are well understood. Producing a baseline on the basis of these forecasts has the merit of consistency, but this comes at the cost of a self-inflicted lack of realism. In addition, the baseline should extend over a longer horizon (see below), which goes beyond the ability to make forecasts.

Historical trends have the advantage over current values of providing some stability, but this stability is illusory. Trend is adequate for GDP growth, which tends to fluctuate around a reasonably stable level, with good years making up for bad years; this is the only historical trend that should be used. The other variables, the exchange and interest rates and the primary balance are potentially volatile and, partly at least, controlled by the authorities. Exploring the debt implication of the current settings is more informative than relying on historical averages that are often outdated.

The horizon should be long, say ten years. As argued in Section 3.3, debt corrections are best carried out slowly, with small changes in the primary account maintained over a long period. Debt corrections are inherently costly, the costlier the sharper they are. The same effect, if sustained, can be achieved at a much lower cost if it is spread on many years.

\subsubsection{Policy Implications}

Projected over a long horizon, the two charts displayed in Figure 5 provide an adequate framework for policy discussions. The impossibility principle means that DSA should not lead to automatic policy conclusions, a fact well recognized in IMF (2003). For this reason, the lighter and more trans- 
parent are the parameter settings, the smaller is the risk of being drawn into giving them an overly prominent role.

The baseline debt projection immediately indicates where the debt is heading to. The debt-stabilizing - or debt-reducing when the debt is deemed excessive and a lower long-run target can be agreed upon - primary account provides a reasonable evaluation of the effort required to achieve debt sustainability.

It is then possible, indeed desirable, to ask "what if?" questions and produce additional charts. In policy discussions, many questions can be asked and easily answered. It is straightforward to produce similar charts showing the mechanical effects on debt and the stabilizing primary account of changes in the interest or growth rates, whether they are permanent or temporary. It is important to keep in mind that such effects are purely mechanical, because they ignore the linkages among the variables that drive the debt accumulation process. For example, changes in the primary current account may require acting on the exchange rate, which in turns will not only affect the debt-GDP ratio but may also imply different interest rate levels.

This resembles the IMF approach to DSA, but it differs in two important ways: 1) there is no pretense of providing forecasts and of assessing their likelihood and 2) they are answers to questions asked by policy-makers and not ready-made suggestions that the debt might be in a danger zone.

\subsubsection{Institutions Matter}

Credibility is an essential component of DSA, yet it is largely hidden. Credibility affects the exchange and interest rate and it can trigger virtuous or vicious circles. The CPIA is one way of recognizing the importance of credibility, but it takes institutions as given. Policy making is not just about setting macroeconomic variables; it should give a prominent role to shaping policy-making institutions.

A number of countries have taken steps to improve their policy-making institutions in the area of fiscal policy, with much success so far. Brazil and Chile, for instance, have adopted formal procedures that bind policy actions within a framework that put debt sustainability at the forefront. Most East Asian countries have informally done so, relying on norms instead of legal arrangements. Mechanical DSA, as discussed in the present paper, implicitly take institutions as given, while CPIA does so explicitly. It would seem important to downplay the mechanical part of DSA and bring up forcefully the contributions that adequate institutions can make to avoiding debt distress. 


\section{References}

Abiad, A., \& Ostry, J.D. (2005). Primary Surpluses and Sustainable Debt Levels in Emerging Market Countries. (IMF Policy Discussion Paper PDP/05/6). International Monetary Fund. http://www.imf.org/external/pubs/ft/pdp/2005/pdp06.pdf

Arnone, M., \& Presbitero, A.F. (2010). Debt Relief Initiatives. Policy Design and Outcome. Farnham, England: Ashgate Publishing.

Arrow, K., Dasgupta, P., Goulder, L., Daily, G., Ehrlich, P., Heal, G., Levin, S., MÃler, K-G., Schneider, S., Starrett, D., \& Walker, B. (2004). Are We Consuming Too Much? Journal of Economic Perspectives, 18(3), 147-172. doi:10.1257/0895330042162377

Blanchard, O.J. (2005). Fiscal Dominance and Inflation Targeting: Lessons from Brazil. In Giavazzi, F., Goldfajn, I., \& Herrera, S. (Eds.). (2005). Inflation Targeting, Debt and the Brazilian Experience (pp. 49-80). Cambridge, MA: MIT Press.

Blanchard, O.J., Chouraqui, J-C., Hagemann, R.P., \& Sartor, N. (1990). The Sustainability of Fiscal Policy: New Answers to an Old Question. OECD Economic Studies, 15: 7-36.

Borensztein, E. \& Panizza, U. (2009). The Costs of Sovereign Default. IMF Staff Papers, 56(4), 683-741. doi:10.1057/imfsp.2009.21

Borensztein, E., Chamon, M., Jeanne, O., Mauro, P., \& Zettelmeyer, J. (2004). Sovereign Debt Structure for Crisis Prevention. (IMF Occasional Paper n. 237). International Monetary Fund. http://www.imf.org/external/pubs/nft/op/237/op237.pdf

Buffie, E.F., Berg, A., Pattillo, C., Portillo, R., \& Zanna, LF. (2010). Public Investment, Growth, and Debt Sustainability: Putting Together the Pieces. Presentation at IMF www.imf.org/external/np/seminars/eng/2010/spr/lic/pdf/ab.pdf.

Buiter, W.H. (1985). A Guide to Public Debts and Deficits. Economic Policy, 1(1), 13-79. doi:10.2307/1344612

Bulow, J., \& Rogoff, K. (1989). A Constant Recontracting Model of Sovereign Debt. Journal of Political Economy, 97(1), 155-178. doi:10.1086/261596

Burda, M.C., \& Wyplosz, C. (in press). Macroeconomics, A European Text (Fifth Edition). Oxford: Oxford University Press, forthcoming. 
Celasun, O., Debrun, X., \& Ostry, J.D. (2006). Primary Surplus Behavior and Risks to Fiscal Sustainability in Emerging Market Countries: A "Fan-Chart" Approach. (IMF Working Paper WP/06/67). International Monetary Fund. http://www.imf.org/external/pubs/ft/wp/2006/wp0667.pdf

Chang, R., \& Velasco, A. (2000). Liquidity Crises in Emerging Markets: Theory and Policy. In Bernanke, B.S., \& Rotemberg, J. (Eds.). NBER Macroeconomics Annual 1999. Cambridge, MA: MIT Press.

Cordella, T., Ricci, L.A., \& Ruiz-Arranz, M. (2010). Debt Overhang or Debt Irrelevance? IMF Staff Papers, 57(1), 1-24. doi:10.1057/imfsp.2009.20

Di Bella, G. (2008). A Stochastic Framework for Public Debt Sustainability Analysis. (IMF Working Paper WP/08/58). International Monetary Fund.

Garcia, M., \& Rigobon, R. (2005). A Risk Management Approach to Emerging Market's Sovereign Debt Sustainability with an Application to Brazilian Data. In Giavazzi, F., Goldfajn, I., \& Herrera, S. (2005). Inflation Targeting, Debt and the Brazilian Experience (pp. 163-188). Cambridge, MA: MIT Press.

Hemming, R., Kell, M., \& Schimmelpfenning, A. (2003). Fiscal Vulnerability and Financial Crises in Emerging Market Economies. (IMF Occasional Paper n. 218). International Monetary Fund.

Hostland, D., \& Karam, P. (2005). Assessing Debt Sustainability in Emerging Market Economies Using Stochastic Simulation Methods. (IMF Working Paper WP/05/226). International Monetary Fund. http://www.imf.org/external/pubs/ft/wp/2005/wp05226.pdf

International Monetary Fund (2002). Assessing Sustainability. http://www.imf.org/external/np/pdr/sus/2002/eng/052802.pdf

International Monetary Fund (2003a). World Economic Outlook. Public Debt in Emerging Markets. Retrieved from http://www.imf.org/external/pubs/ft/weo/2003/02/index.htm

International Monetary Fund (2003b) Sustainability AssessmentsReview of Application and Methodological Refinements. Retrieved from http://www.imf.org/external/np/pdr/sustain/2003/061003.pdf

International Monetary Fund 6 International Development Association (2004). Debt Sustainability in Low-Income Countries: Further Considerations on an Operational Framework and Policy Implications. Retrieved from http://www.imf.org/external/np/pdr/sustain/2004/091004.pdf

$\begin{array}{cccccc}\text { International } & \text { Monetary } & \text { Fund } & (2005 a) \text {. Information Note on } \\ \text { Modifications to the Fund's } & \text { Debt Sustainability Assessment }\end{array}$


Framework for Market Access Countries. Retrieved from http://www.imf.org/external/np/pp/eng/2005/070105.htm

\begin{tabular}{|c|c|c|c|c|c|}
\hline International & & ary & Fund & $(2005 b)$ & $M F$ \\
\hline Country & Report & No. & 05/392. & Retrieve & from \\
\hline
\end{tabular}

International Monetary Fund (2005c). Are Fund Staff Projections of Debt More Optimistic Under Program Contexts? Retrieved from http://www.imf.org/external/np/pp/eng/2005/110905.pdf

International Monetary Fund (2005d). IMF Country Report No. 05/345. Retrieved from http://www.imf.org/external/pubs/ft/scr/2005/cr05345.pdf

International Monetary Fund and World Bank (2009). A Review of Some Aspects of the Low-Income Country Debt Sustainability Framework. Retrieved from http:/ / www.imf.org/external/np/pp/eng/2009/080509a.pdf

Jeanne, O., \& Zettelmeyer, J. (2001). International Bailouts, Moral Hazard and Conditionality. Economic Policy, 16(33), 407-432. doi:10.1111/14680327.00080

Kraay, A., \& Nehru, V. (2003). When Is External Debt Sustainable? International Monetary Fund Research Workshop. Retrieved from http://www.imf.org/external/np/res/seminars/2003/lic/pdf/kn.pdf

Manasse, P., Roubini, N., \& Schimmelpfenning, A. (2003). Predicting Sovereign Debt Crises. (IMF Working Paper WP/03/221). International Monetary Fund. http://info.worldbank.org/etools/docs/library/ 156232/restructuring2004/pdf/wp03221.pdf

Missale, A. (2000). Public Debt Management. Oxford: Oxford University Press.

Reinhart, C.M., \& Belen Sbrancia, M. (2011). The Liquidation of Government Debt. (NBER Working Paper No. 16893). Retrieved from National Bureau of Economic Research website: http:/ / www.nber.org/papers/w16893.

Rodrik, D. (1998). Who Needs Capital-Account Convertibility? In Fischer, S., Fischer, S., Cooper, R.N., Dornbusch, R., Garber, P.M., Massad, C., Polak, J.J., Rodrik, D., \& Tarapore, S.S. Should the IMF Pursue Capital-Account Convertibility? (pp.55-65). Princeton, New Jersey: International Finance Section, Department of Economics, Princeton University.

World Bank (2004). Country Policy and Institutional Assessments: An External Panel Review Panel Recommendations and Management Follow-up. Retrieved from: 
http:/ / siteresources.worldbank.org/IDA/Resources/CPIAExpPanRepSecM2004-0304.pdf

Wyplosz, C. (2005a). Institutions for Debt Stability in Brazil. In Giavazzi, F., Goldfajn, I., \& Herrera, S. (Eds.). (2005). Inflation Targeting, Debt and the Brazilian Experience (pp. 193-222). Cambridge, MA: MIT Press.

Wyplosz, C. (2005b). Fiscal Policy: Institutions Versus Rules. National Institute Economic Review, 191(1), 70-84. doi:10.1177/0027950105052661 


\section{Appendix: An Alternative Debt Sustainability Con- dition}

Section 2.1 suggests an alternative definition of debt sustainability. This appendix briefly characterizes the link of this definition with the solvency condition.

Let $B_{t}$ be the debt outstanding at beginning of period $t, R_{t, t+i}$ the interest factor between periods $t$ and $t+i$, and $S_{t}$ the primary budget balance. The debt accumulation process implies:

$$
R_{t, t+n} B_{t+n}=B_{t}-\sum_{i=0}^{n} R_{t, t+i} S_{t+i}
$$

Solvency is defined by the usual transversality condition:

$$
\lim _{n \rightarrow \infty} R_{t, t+n} B_{t+n} \leq 0
$$

which can be rewritten as:

$$
B_{t} \leq \sum_{i=0}^{\infty} R_{t, t+i} S_{t+i}
$$

The net worth of the entity (government, country) is:

$$
V_{t}=\sum_{i=0}^{\infty} R_{t, t+i} S_{t+i}-B_{t}
$$

and solvency simply requires $V_{t} \geq 0$.

The alternative sustainability condition is that $V_{t}$ be trend-increasing, i.e.: $V_{t+n}-V_{t} \geq 0$ for most $n$.

Thus, it may be that initially $V_{t} \leq 0$ but the sustainability condition implies that there exists a horizon $N$ such that, for all $n>N, V_{t+n} \geq 0$. 